\title{
Correction to: Patient Contribution to the Development and Safe Use of Medicines During the Covid-19 Pandemic
}

\author{
Peter J. Pitts ${ }^{1}$ - François Houÿez ${ }^{2}$
}

Published online: 5 November 2020

(c) The Drug Information Association, Inc 2020 https://doi.org/10.1007/s43441-020-00235-y

There is a typographical error in the original article's Acknowledgements section. The corrected version follows:

\section{Acknowledgements}

The authors submit this report based on the work of the CIOMS WG $\mathrm{XI}$, focusing on patient involvement in the development and safe use of medicines, CIOMS has been working diligently with patient organisations, academia, pharmaceutical industry, and health authorities to help address the questions raised in this Statement and other issues. The CIOMS WG XI report is expected to be published in 2021. CIOMS Working Group WG XI: Patient involvement in the development and safe use of medicines. For more information about the Working Group and its members, please visit: https://cioms.ch/working-groups/worki ng-group-xi-patient-involvement/.
The original article can be found online at https://doi.org/10.1007/ s43441-020-00235-y.

Peter J. Pitts

ppitts@cmpi.org

1 Descartes Medical School, Center for Medicine in the Public Interest, University of Paris, Paris, France

2 EURORDIS, Paris, France 